\title{
Bleeding Complications and Adverse Events After Desmopressin Acetate for Percutaneous Renal Transplant Biopsy
}

Quan Yao $\underline{\mathrm{Ho}},{ }^{1}{ }^{M B B S}(S G P)$, MRCP (SGP), FAMS, Cynthia C $\underline{\operatorname{Lim}},{ }^{1} M B B S(S G P)$, MMed (SGP), MRCP (Edin), Sobhana Thangaraju, ${ }^{1} M B B S(S G P), M R C P(U K), F A M S$, Benson $\underline{\text { Siow, }}{ }^{2}{ }_{B S c}$ (Hons), Yok Mooi Chin, ${ }^{1}{ }_{A d v}$ Dip (Biotech), Ying $\underline{\text { Hao }},{ }^{3}$ PhD, Puay Hoon Lee, ${ }^{2}$ PharmD, Marjorie Foo, ${ }^{1} M B C h B, F R C P, F A M S$, Chieh Suai Tan, ${ }^{1}$ MBBS (SGP), MRCP (UK), FAMS, Terence $\underline{\text { Kee, }}{ }^{1}$ BMBS (Flinders), FRCP, FAMS

\begin{abstract}
Introduction: Percutaneous renal biopsy remains critical for the workup of renal allograft dysfunction but is associated with the risk of bleeding. Prophylactic intravenous desmopressin has been proposed to reduce bleeding risk in native renal biopsies, but its efficacy in the renal transplant population is unclear and adverse events such as severe hyponatraemia have been reported. Materials and Methods: We conducted a single-centre retrospective cohort study involving adult ( $\geq 21$ years old) renal transplant recipients with impaired renal function (serum creatinine $\geq 150 \mu \mathrm{mol} / \mathrm{L}$ ) who underwent ultrasound-guided renal allograft biopsies from 2011-2015 to investigate the effect of prebiopsy desmopressin on the risk of bleeding and adverse events. Results: Desmopressin was administered to 98 of 195 cases who had lower renal function, lower haemoglobin and more diuretic use. Postbiopsy bleeding was not significantly different between the 2 groups (adjusted odds ratio $[\mathrm{OR}] \mathbf{0 . 7 9}, 95 \%$ confidence interval $[\mathrm{CI}] \mathbf{0 . 2 6}-\mathbf{2 . 4 3}, P=0.68$ ) but desmopressin increased the risk of postbiopsy hyponatraemia (sodium $[\mathrm{Na}]<135 \mathrm{mmol} / \mathrm{L}$ ) (adjusted OR 2.24, 95\% CI 1.10-4.59, $P=\mathbf{0 . 0 3})$. Seven cases of severe hyponatraemia $(\mathrm{Na}<125$ $\mathrm{mmol} / \mathrm{L}$ ) developed in the desmopressin group, while none did in the non-desmopressin group. Amongst those who received desmopressin, risk of hyponatraemia was lower (OR $0.26,95 \% \mathrm{CI} 0.09-0.72, P=0.01$ ) if fluid intake was $<1 \mathrm{~L}$ on the day of biopsy. Conclusion: Prophylactic desmopressin for renal allograft biopsy may be associated with significant hyponatraemia but its effect on bleeding risk is unclear. Fluid restriction (where feasible) should be recommended when desmopressin is used during renal allograft biopsy. A randomised controlled trial is needed to clarify these outcomes.
\end{abstract}

Ann Acad Med Singapore 2020;49:52-64

Key words: Adverse effects, Deamino arginine vasopressin, Haematoma, Haemorrhage, Hyponatraemia

\section{Introduction}

Renal allograft biopsy remains critical for the diagnosis and management of renal dysfunction amongst renal transplant recipients but is associated with the risk of complications. ${ }^{1-5}$ Bleeding complications include gross haematuria and perinephric haematoma which may lead to urinary tract obstruction, ${ }^{6}$ Page kidney, ${ }^{7}$ blood transfusions, bladder irrigation, radiological, cystoscopic or surgical interventions, ${ }^{2}$ increased length of hospitalisation, ${ }^{8,9}$ graft loss and even death. ${ }^{10}$ Treatment for these complications may be associated with further adverse events such as allo-sensitisation (with blood transfusions) ${ }^{11}$ and contrastinduced nephropathy (with the use of iodinated contrast).
The reported risk of bleeding complications after renal allograft biopsy from previous studies is $1.8-10.3 \%$. $^{2,6,10,12-14}$ Desmopressin acetate, otherwise known as 1-Deamino-8-DArginine Vasopressin (DDAVP), has been shown to reduce bleeding complications in native renal biopsies of patients with both normal ${ }^{15}$ and impaired renal function. ${ }^{16}$ However, its efficacy is unclear for renal allograft biopsies and severe hyponatraemia has been reported. ${ }^{17}$ Other previously reported adverse effects of DDAVP include thrombotic events such as acute myocardial infarctions ${ }^{18,19}$ and minor effects such as headache, flushing and diarrhoea. ${ }^{20,21}$

We sought to investigate the effect of prebiopsy singledose intravenous DDAVP on the risk of postbiopsy bleeding

${ }^{1}$ Department of Renal Medicine, Singapore General Hospital, Singapore

${ }^{2}$ Department of Pharmacy, Singapore General Hospital, Singapore

${ }^{3}$ Division of Medicine, Singapore General Hospital, Singapore

Address for Correspondence: Dr Ho Quan Yao, Department of Renal Medicine, Singapore General Hospital, Outram Road, Singapore 169608.

Email: ho.quan.yao@singhealth.com.sg 
and severe adverse events such as hyponatraemia and thrombotic events in our renal transplant recipients with impaired renal function who underwent ultrasound-guided percutaneous allograft biopsies.

\section{Materials and Methods}

Study Design

We performed a retrospective chart review of all percutaneous renal allograft biopsies in adult ( $\geq 21$ years old) renal transplant recipients with impaired renal function (serum creatinine $\geq 150 \mu \mathrm{mol} / \mathrm{L}$ ) in the Singapore General Hospital between 2011-2015. Singapore General Hospital is a tertiary academic centre and is 1 of 2 transplant centres in Singapore, with $>800$ renal transplant recipients on active follow-up. Patients were identified from a procedure log of renal biopsies performed by nephrologists and interventional radiologists.

All biopsies were performed based on clinical indications. Patients were routinely admitted and observed for at least 24 hours postbiopsy. Baseline renal function, electrolytes, full blood count and coagulation profile with activated partial thromboplastin time (aPTT) and prothrombin time (PT) were performed within 3 days prior to renal biopsy. Relative contraindications for biopsy include systolic blood pressure $>160 \mathrm{mmHg}$ and use of antiplatelets or anticoagulants.

DDAVP was administered as a single intravenous dose within an hour before biopsy. The recommended dose of DDAVP in our institution is $0.3 \mu \mathrm{g} / \mathrm{kg}$. Its use was left to the discretion of individual physicians but was suggested if patients had serum urea $>15 \mathrm{mmol} / \mathrm{L}$, serum creatinine $>200 \mu \mathrm{mol} / \mathrm{L}$ or estimated glomerular filtration rate (eGFR) $<30 \mathrm{ml} / \mathrm{min} / 1.73 \mathrm{~m}^{2}$.

All biopsies were performed under direct ultrasound guidance using a 16-gauge automated spring-loaded gun (Bard ${ }^{\circledR}$ Magnum $^{\circledR}$ Reusable Core Biopsy System, Bard Biopsy Systems, United States; or BioPince ${ }^{\mathrm{TM}}$ Full Core Biopsy Instrument, Argon Medical Devices, United States). Adequacy of samples was confirmed immediately by a trained laboratory technician using light microscopy. Following the biopsy, patients were instructed to lie supine for at least 6 hours and observed for at least 24 hours. Repeat investigations such as blood count, electrolytes, including serum sodium, and imaging of the renal allograft were not routine and were repeated based on clinical indications.

\section{Outcomes and Measurements}

The primary outcome was postbiopsy bleeding. Bleeding complications were classified (similar to previous studies) $)^{6,13,14,22}$ as minor bleeding-defined as gross haematuria or radiologically-confirmed perinephric haematoma not requiring intervention-and major bleeding-defined as need for blood transfusion, bladder irrigation, radiological, cystoscopic or surgical intervention or death. Secondary outcomes were hyponatraemia and thrombotic events. Hyponatraemia and severe hyponatraemia were defined by serum sodium $<135 \mathrm{mmol} / \mathrm{L}$ and $<125 \mathrm{mmol} / \mathrm{L}$, respectively, within 3 days postbiopsy. The half-life of DDAVP is found to be 2-3 times longer in patients with renal impairment and its effect on urine osmolarity can last up to 48 hours. ${ }^{23}$ As such, we selected 3 days as the cutoff for the detection of hyponatraemia in our study. Thrombotic events were defined as any thrombotic events that occurred within 2 weeks postbiopsy including acute myocardial infarction, deep vein thrombosis, pulmonary embolism, arteriovenous fistula, graft thrombosis or renal artery or vein thrombosis.

The following data were retrieved from electronic medical records: patient demographic, cause of end-stage renal disease (ESRD), transplant characteristics (e.g. type and vintage of transplant, maintenance immunosuppression), comorbidities, fluid intake on the day of biopsy, laboratory values (e.g. prebiopsy haemoglobin, PT, aPTT, platelet, serum sodium, urea, creatinine, urine protein-to-creatinine ratio) within 3 days before biopsy and medications that may affect risk of bleeding ${ }^{3}$ (e.g. DDAVP, antiplatelets, anticoagulants) or hyponatraemia ${ }^{24}$ (e.g. diuretics, intravenous immunoglobulins, opioids, non-steroidal anti-inflammatory drugs, antiepileptics, antidepressants, antipsychotics, co-trimoxazole, ciprofloxacin) within 2 weeks of biopsy. All laboratory investigations were performed in the central laboratory which is accredited by the College of American Pathologists. eGFR was calculated using the Modification of Diet in Renal Disease equation.

\section{Statistical Analysis}

Results are expressed as median and interquartile range ( $25^{\text {th }}$ and $75^{\text {th }}$ percentiles) for continuous data and as frequency and percentage for categorical data. MannWhitney U test was used to compare continuous variables while Pearson chi-square test or Fisher's Exact test was used for categorical variables. Univariable and multivariable logistic regression were performed to estimate the odds ratio (OR) and adjusted OR, respectively, for each risk factor of bleeding and hyponatraemia. Factors with $P<0.10$ on univariable analysis were selected for multivariate analysis. All analyses were performed using SPSS for Windows (release 17.0) and R version 3.5.1.25 2 -sided $P<0.05$ was considered statistically significant.

\section{Ethics Approval}

This study abided by the Declaration of Helsinki and waiver of informed consent for this retrospective electronic 
medical records review was approved by the local institutional review board (CIRBE 2017/2647).

\section{Results}

We performed 195 renal allograft biopsies in 142 patients from June 2011 to July 2015. Ninety-eight biopsies were performed with prebiopsy intravenous DDAVP (DDAVP group) and 97 without (non-DDAVP group). No cases were lost to follow-up.

Baseline characteristics of both groups are listed in Table 1. The DDAVP group had worse renal function, lower prebiopsy haemoglobin and a higher proportion of loop diuretic use.

\section{Bleeding}

The rates of bleeding complications are summarised in Table 2. Incidence of overall, major and minor bleeding were not different between biopsies with and without DDAVP prophylaxis. Additional adjustment for eGFR still showed that DDAVP use did not significantly impact bleeding risk (adjusted OR 0.79, 95\% confidence interval [CI] 0.26-2.43, $P=0.68)$.

Other factors found to be significantly associated with overall bleeding complications include prebiopsy haemoglobin $<8 \mathrm{~g} / \mathrm{dL}$ (OR 6.30, 95\% CI 1.69-23.5, $P=$ 0.006 ), platelets $<200 \times 10^{9} / \mathrm{L}$ (OR $3.48,95 \%$ CI $1.21-10.0$, $P=0.02)$ and diabetes mellitus as the cause of ESRD (OR $10.16,95 \%$ CI $2.58-38.96, P=0.001)$. DDAVP did not significantly alter the bleeding risk even with adjustment for each of these risk factors. Conversely, lower haemoglobin and platelet count and diabetes as the causes of ESRD remained significantly associated with bleeding after adjustment for DDAVP(see Supplementary Tables 1 and 2).

\section{DDAVP-Related Adverse Events}

Almost all cases $(\mathrm{n}=177,90.8 \%)$ had serum sodium repeated within 3 days after biopsy. Table 2 shows that those administered DDAVP were more likely to have

Table 1. Baseline Characteristics According to Prebiopsy Desmopressin Acetate Administration

\begin{tabular}{|c|c|c|c|}
\hline Variable & $\begin{array}{l}\text { DDAVP } \\
(n=98)\end{array}$ & $\begin{array}{c}\text { Non-DDAVP } \\
(\mathbf{n}=\mathbf{9 7})\end{array}$ & $\begin{array}{c}P \\
\text { Value }\end{array}$ \\
\hline Age, years (IQR) & $50.6(15.3)$ & $50.6(13.8)$ & 0.81 \\
\hline Ethnicity, n (\%) & & & 0.63 \\
\hline Chinese & $61(62.2)$ & $68(70.1)$ & \\
\hline Indian & $10(10.2)$ & $6(6.2)$ & \\
\hline Others & $4(4.1)$ & $4(4.1)$ & \\
\hline Renal disease and transplant characteristics & & & 0.10 \\
\hline \multicolumn{4}{|l|}{ Cause of ESRD, n (\%) } \\
\hline Glomerulonephritis & $64(65.3)$ & $73(75.3)$ & \\
\hline Hypertension & $9(9.2)$ & $4(4.1)$ & \\
\hline Diabetes mellitus & $4(4.1)$ & $8(8.2)$ & \\
\hline Others/unknown & $21(21.4)$ & $12(12.4)$ & \\
\hline Type of transplant, n (\%) & & & 0.10 \\
\hline Living donor & $30(31.3)$ & $42(43.3)$ & \\
\hline Deceased donor & $66(68.8)$ & $55(56.7)$ & \\
\hline Years since transplant (IQR) & $5.35(11.63)$ & $3.68(8.22)$ & 0.33 \\
\hline \multicolumn{4}{|l|}{ Maintenance immunosuppression, n (\%) } \\
\hline Prednisolone & $97(99.0)$ & $96(99.0)$ & 1.00 \\
\hline Tacrolimus & $45(45.9)$ & $51(52.6)$ & 0.39 \\
\hline Cyclosporin A & $43(43.9)$ & $38(39.2)$ & 0.56 \\
\hline Mycophenolate & $74(75.5)$ & $80(82.5)$ & 0.29 \\
\hline Azathioprine & $6(6.1)$ & $6(6.2)$ & 1.00 \\
\hline Sirolimus & $3(3.1)$ & $4(4.1)$ & 0.72 \\
\hline
\end{tabular}

DDAVP: Desmopressin acetate; eGFR: Estimated glomerular filtration rate; ESRD: End-stage renal disease; IQR: Interquartile range; NA: Not applicable 
Table 1. Baseline Characteristics According to Prebiopsy Desmopressin Acetate Administration (Cont'd)

\begin{tabular}{|c|c|c|c|}
\hline Variable & $\begin{array}{l}\text { DDAVP } \\
(\mathrm{n}=98)\end{array}$ & $\begin{array}{c}\text { Non-DDAVP } \\
(\mathrm{n}=97)\end{array}$ & $\begin{array}{c}P \\
\text { Value }\end{array}$ \\
\hline \multicolumn{4}{|l|}{ Comorbidities } \\
\hline Diabetes mellitus, n (\%) & $28(28.6)$ & $19(19.6)$ & 0.18 \\
\hline Ischaemic heart disease, $\mathrm{n}(\%)$ & $9(9.2)$ & $7(7.2)$ & 0.80 \\
\hline Congestive cardiac failure, n (\%) & $0(0)$ & $0(0)$ & NA \\
\hline Liver cirrhosis, $\mathrm{n}(\%)$ & $0(0)$ & $0(0)$ & NA \\
\hline \multicolumn{4}{|l|}{ Clinical parameters } \\
\hline Weight, kg (IQR) & $67.4(22.4)$ & $67.7(19.2)$ & 0.79 \\
\hline Body mass index (IQR) & $25.9(6.5)$ & $24.6(6.1)$ & 0.40 \\
\hline Diastolic blood pressure, mmHg (IQR) & $70.5(13)$ & $80(10)$ & 0.11 \\
\hline \multicolumn{4}{|l|}{ Prebiopsy laboratory } \\
\hline Haemoglobin, g/dL (IQR) & $10.3(2.1)$ & $11.0(2.4)$ & 0.03 \\
\hline Platelets, × 10/L (IQR) & $240(121)$ & $226(106)$ & 0.38 \\
\hline Prothrombin time, seconds (IQR) & $10.3(0.8)$ & $10.3(0.7)$ & 0.83 \\
\hline Activated partial thromboplastin time, seconds (IQR) & $26.4(2.4)$ & $27.1(3.2)$ & 0.31 \\
\hline Urea, mmol/L (IQR) & $14.8(7.1)$ & $10.7(5.4)$ & $<0.001$ \\
\hline Creatinine, $\mu \mathrm{mol} / \mathrm{L}(\mathrm{IQR})$ & $280.5(177)$ & $190(91)$ & $<0.001$ \\
\hline eGFR, mL/min/1.73 m² (IQR) & $19.0(11.94)$ & $30.4(19.77)$ & $<0.001$ \\
\hline Urine protein-to-creatinine ratio, g/g (IQR) & $1.11(2.70)$ & $0.80(3.34)$ & 0.17 \\
\hline Nephrotic range proteinuria, $\mathrm{n}(\%)$ & $30(32.6)$ & $30(33.7)$ & 1.00 \\
\hline Prebiopsy sodium, mmol/L (IQR) & $138(4)$ & $138(5)$ & 0.26 \\
\hline Antiplatelet use, n (\%) & $1(1.0)$ & $0(0)$ & NA \\
\hline Anticoagulation use, n (\%) & $0(0)$ & $0(0)$ & NA \\
\hline Fresh frozen plasma use, n (\%) & $2(2.0)$ & $0(0)$ & NA \\
\hline Vitamin K use, n (\%) & $1(1.0)$ & $0(0)$ & NA \\
\hline Antihypertensive use, n (\%) & $82(83.7)$ & $82(84.5)$ & 1.00 \\
\hline Diuretic use, n (\%) & $43(43.9)$ & $20(20.6)$ & 0.001 \\
\hline Loop diuretics, n (\%) & $43(43.9)$ & $17(17.5)$ & $<0.001$ \\
\hline Thiazides, n (\%) & $1(1.0)$ & $3(3.1)$ & 0.62 \\
\hline Potassium-sparing, n (\%) & $4(4.1)$ & $2(2.1)$ & 0.68 \\
\hline Intravenous immunoglobulins use, n (\%) & $3(3.1)$ & $7(7.2)$ & 0.21 \\
\hline Fluid intake on day of biopsy, litres (IQR) & $1.35(1.05)$ & $1.45(1.16)$ & 0.92 \\
\hline Dose of DDAVP, $\mu \mathrm{g}(\mathrm{IQR})$ & $12.0(4.0)$ & NA & NA \\
\hline Dose of DDAVP per body weight, $\mu \mathrm{g} / \mathrm{kg}$ (IQR) & $0.20(0.06)$ & NA & NA \\
\hline
\end{tabular}

DDAVP: Desmopressin acetate; eGFR: Estimated glomerular filtration rate; ESRD: End-stage renal disease; IQR: Interquartile range; NA: Not applicable

hyponatraemia and had a greater drop in serum sodium. In multivariable modelling (Table 3), DDAVP remained independently associated with postbiopsy hyponatraemia (adjusted OR 2.73, 95\% CI 1.20-6.22, $P=0.02$ ) after adjustment for eGFR, prebiopsy sodium, fluid intake on day of biopsy, diuretics, intravenous immunoglobulin (IVIG) use and type of renal transplant. Seven cases in the
DDAVP group developed severe hyponatraemia while none did in the non-DDAVP group (see Supplementary Tables 3 and 4). Amongst the cases of severe hyponatraemia, 1 developed mild symptoms requiring correction with $3 \%$ sodium chloride, while another developed seizures and required high dependency ward admission and 3\% sodium chloride infusion. 
Table 2. Postbiopsy Bleeding and Adverse Events According to Prebiopsy Desmopressin Acetate Administration

\begin{tabular}{|c|c|c|c|}
\hline Variable & $\begin{array}{l}\text { DDAVP } \\
(\mathrm{n}=98)\end{array}$ & $\begin{array}{c}\text { Non-DDAVP } \\
(\mathrm{n}=97)\end{array}$ & $\begin{array}{c}P \\
\text { Value }\end{array}$ \\
\hline Overall bleeding complications, $\mathrm{n}(\%)$ & $8(8.2)$ & $8(8.2)$ & 1.00 \\
\hline Gross haematuria, n (\%) & $5(5.1)$ & $3(3.1)$ & 0.72 \\
\hline Radiologically-confirmed perinephric haematoma, n (\%) & $1(1.0)$ & $6(6.2)$ & 0.12 \\
\hline Blood transfusion, $\mathrm{n}(\%)$ & $4(4.1)$ & $1(1.0)$ & 0.37 \\
\hline Bladder irrigation, $\mathrm{n}(\%)$ & $2(2.0)$ & $1(1.0)$ & 1.00 \\
\hline Cystoscopy, n (\%) & $0(0.0)$ & $0(0.0)$ & NA \\
\hline Radiological intervention, $\mathrm{n}(\%)$ & $1(1.0)$ & $0(0.0)$ & NA \\
\hline Surgery, n (\%) & $0(0.0)$ & $0(0.0)$ & NA \\
\hline Death, n (\%) & $0(0.0)$ & $0(0.0)$ & NA \\
\hline \multicolumn{4}{|l|}{ Adverse events } \\
\hline Hyponatraemia, n (\%) & $43(46.7)$ & $27(31.8)$ & 0.047 \\
\hline Severe hyponatraemia, n (\%) & $7(7.6)$ & $0(0.0)$ & NA \\
\hline Change in serum sodium, mmol/L (IQR) & $-4.0(5.0)$ & $-1.0(5.0)$ & $<0.001$ \\
\hline Thrombotic events, $\mathrm{n}(\%)$ & $0(0)$ & $0(0)$ & NA \\
\hline
\end{tabular}

DDAVP: Desmopressin acetate; IQR: Interquartile range; NA: Not applicable

Table 3. Risk Factors for Hyponatraemia

\begin{tabular}{|c|c|c|c|c|c|c|}
\hline \multirow[t]{2}{*}{ Variable } & \multicolumn{3}{|c|}{ Univariable Model } & \multicolumn{3}{|c|}{ Multivariable Model } \\
\hline & OR & $95 \%$ CI & $P$ Value & Adjusted OR & $95 \%$ CI & $P$ Value \\
\hline DDAVP use & 1.89 & $1.02-3.48$ & 0.04 & 3.20 & $1.35-7.57$ & 0.008 \\
\hline Prebiopsy serum sodium, per $\mathrm{mmol} / \mathrm{L}$ increment & 0.75 & $0.66-0.85$ & $<0.001$ & 0.73 & $0.63-0.85$ & $<0.001$ \\
\hline Fluid intake, per $100 \mathrm{~mL}$ increment & 1.06 & $1.00-1.08$ & 0.03 & 1.06 & $1.01-1.11$ & 0.01 \\
\hline IVIG use & 3.85 & $0.96-15.44$ & 0.06 & 5.34 & $1.01-28.21$ & 0.048 \\
\hline DDRT (vs LDRT) & 0.50 & $0.27-0.93$ & 0.03 & 0.55 & $0.25-1.18$ & 0.12 \\
\hline
\end{tabular}

CI: Confidence interval; DDAVP: Desmopressin acetate; DDRT: Deceased donor renal transplant; eGFR: Estimated glomerular filtration rate;

IVIG: Intravenous immunoglobulin; LDRT: Living donor renal transplant; OR: Odds ratio

DDAVP was used in 10 of 25 cases with prebiopsy hyponatraemia and resulted in a greater reduction in postbiopsy serum sodium compared to those without DDAVP $(-7.0 \mathrm{mmol} / \mathrm{L}$ vs $+1.0 \mathrm{mmol} / \mathrm{L}, P=0.03)$. After excluding cases with prebiopsy hyponatraemia, DDAVP remained significantly associated with postbiopsy hyponatraemia (43.5\% vs $23.9 \%$, OR $2.45,95 \%$ CI $1.22-4.90, P=0.01)$.

Medications associated with hyponatraemia such as opioids ( $\mathrm{n}=26)$, co-trimoxazole $(\mathrm{n}=14)$, omeprazole ( $\mathrm{n}$ $=16)$, IVIG $(n=10)$, ciprofloxacin $(n=6)$ and haloperidol $(\mathrm{n}=1)$ were administered within 2 weeks prior to biopsy in 42 cases. Antidepressants, antiepileptics or non-steroidal anti-inflammatory drugs were not used. These medications were not associated with postbiopsy hyponatraemia and exclusion of these 42 cases did not alter the association between DDAVP and hyponatraemia ( $46.5 \%$ vs $28.8 \%$, OR $2.15,95 \%$ CI $1.06-4.31, P=0.04)$. No thrombotic events were detected in our study.

\section{DDAVP Subgroup}

Among the 98 cases who received DDAVP, higher fluid intake was associated with hyponatraemia (adjusted OR 1.22 per $100 \mathrm{~mL}$ increment, $95 \%$ CI $1.10-1.36, P<0.001$ ), while diuretic use (adjusted OR $0.28,95 \%$ CI $0.09-0.86, P$ $=0.03$ ) and higher prebiopsy sodium (adjusted OR 0.58 per $1 \mathrm{mmol} / \mathrm{L}$ increment, $95 \%$ CI $0.42-0.79, P<0.001)$ were 
protective. Those who developed hyponatraemia had lower median prebiopsy sodium $(137 \mathrm{mmol} / \mathrm{L}$ vs $139 \mathrm{mmol} / \mathrm{L}, P$ $<0.001)$ and higher median biopsy day fluid intake (1717 $\mathrm{mL}$ vs $1100 \mathrm{~mL}, P=0.001)$. Risk of hyponatraemia was lower (OR $0.26,95 \%$ CI $0.09-0.72, P=0.01$ ) and cases of severe hyponatraemia was absent among those with fluid intake of $<1 \mathrm{~L}$ on the day of biopsy.

\section{Discussion}

Our study suggests that prebiopsy intravenous DDAVP for percutaneous renal allograft biopsy may increase the risk of hyponatraemia but may not alter the risk of bleeding.

While the use of DDAVP to reduce the risk of bleeding during renal allograft biopsies was previously reported (Table 4), there were no previous studies investigating its efficacy and safety in the renal transplant population. The only randomised controlled trial (RCT) ${ }^{15}$ included only native renal biopsies in patients with normal renal function (eGFR $\geq 60 \mathrm{~mL} / \mathrm{min} / 1.73 \mathrm{~m}^{2}$ ) and suggested that DDAVP can reduce the development of peri-nephric haematomas. The study also showed that DDAVP reduced the size of haematomas and length of hospitalisation but had no effect on the risk of major complications (i.e. the development of arteriovenous fistulas, need for angiography, embolisation or surgery). A recent pilot retrospective study ${ }^{16}$ with multi-centre registry data showed that DDAVP prior to native renal biopsies reduces the risk of overall and major complications in patients with serum creatinine of $>150 \mu \mathrm{mol} / \mathrm{L}$. Another study has further supported that the beneficial effect of DDAVP may be greater in patients with worse renal function. ${ }^{26}$

The mechanism by which DDAVP might reduce the risk of bleeding in the setting of renal impairment is not exactly understood. DDAVP increases circulating levels of von Willebrand factor and factor VIII and enhances platelet adhesion. ${ }^{27}$ Several studies demonstrated that DDAVP reduces bleeding time in patients with renal impairment. ${ }^{28-30}$ However, more recent studies have also found that bleeding

Table 4. Previously Reported Use of DDAVP for Renal Allograft Biopsy

\begin{tabular}{|c|c|c|c|c|c|}
\hline $\begin{array}{l}\text { Authors, } \\
\text { Country (Year) }\end{array}$ & $\begin{array}{c}\text { Number of Transplant } \\
\text { Biopsies (Transplant }+ \\
\text { Native Biopsies) }\end{array}$ & $\begin{array}{c}\text { Number of Transplant } \\
\text { Biopsies With DDAVP } \\
\text { Used (\%) }\end{array}$ & $\begin{array}{c}\text { Criteria for Use of } \\
\text { DDAVP }\end{array}$ & Dose of DDAVP & $\begin{array}{c}\text { Effects of DDAVP } \\
\text { on Outcomes and } \\
\text { Adverse Events }\end{array}$ \\
\hline $\begin{array}{l}\text { Reschen et al, } \\
\text { UK (2018)* }\end{array}$ & 107 & $23(21.5)$ & $\mathrm{Cr}>250 \mu \mathrm{mol} / \mathrm{L}$ & $\begin{array}{c}0.4 \mu \mathrm{g} / \mathrm{kg}(\max \text { dose } \\
28 \mu \mathrm{g})\end{array}$ & $\begin{array}{c}\text { - No comparative } \\
\text { analysis } \\
\text { - 1 DDAVP patient } \\
\text { developed gross } \\
\text { haematuria } \\
\text { - Adverse events: NR }\end{array}$ \\
\hline $\begin{array}{l}\text { Ferguson et al, } \\
\text { Croatia }(2018)^{\dagger}\end{array}$ & $592(725)$ & NR (82 in total cohort) & $\begin{array}{c}\mathrm{eGFR}<30-45 \mathrm{~mL} / \\
\mathrm{min} / 1.73 \mathrm{~m}^{2}\end{array}$ & $0.4 \mu \mathrm{g} / \mathrm{kg}$ & NR \\
\hline $\begin{array}{l}\text { Whittier et al, } \\
\text { USA (2018) }\end{array}$ & $938(1705)$ & NR & $\begin{array}{l}\text { "At discretion of } \\
\text { attending nephrologist" }\end{array}$ & NR & NR \\
\hline $\begin{array}{l}\text { Feldmann et al, } \\
\text { Germany }(2017)^{\S}\end{array}$ & $181(500)$ & NR (5 in total cohort) & $\begin{array}{l}\text { "Pathological findings in } \\
\text { specific tests" }\end{array}$ & NR & NR \\
\hline $\begin{array}{l}\text { Tsai SF et al, } \\
\text { Taiwan, ROC } \\
(2016)^{\prime}\end{array}$ & 269 & $269(100)$ & All patients & $\begin{array}{l}4 \text { units, } 30 \text { minutes } \\
\text { before biopsy }\end{array}$ & $\begin{array}{l}\text { - No control (non- } \\
\text { DDAVP) group } \\
\text { - No thrombosis or } \\
\text { hyponatraemia }\end{array}$ \\
\hline $\begin{array}{l}\text { Morgan TA et al, } \\
\text { USA }(2016)^{\uparrow}\end{array}$ & 235 (total cohort 2514) & $9(3.8)$ & $\begin{array}{l}\text { "Given prophylactically } \\
\text { to treat platelet } \\
\text { dysfunction" }\end{array}$ & NR & $\begin{array}{c}\text { - More DDAVP } \\
\text { use in group with } \\
\text { complications }(8.5 \% \text { vs } \\
2.7 \%, P=0.08) \\
\text { - Adverse events: NR }\end{array}$ \\
\hline
\end{tabular}

Cr: Creatinine; DDAVP: Desmopressin acetate; eGFR: Estimated glomerular filtration rate; NR: Not reported; ROC: Republic of China; UK: United Kingdom; USA: United States of America

"Reschen ME, Mazzella A, Sharples E. A retrospective analysis of the utility and safety of kidney transplant biopsies by nephrology trainees and consultants. Ann Med Surg (Lond) 2018;28:6-10.

FFerguson C, Winters S, Jackson S, McToal M, Low G. A retrospective analysis of complication and adequacy rates of ultrasound-guided native and transplant non-focal renal biopsies. Abdom Radiol (NY) 2018;43:2183-9.

*Whittier WL, Gashti C, Saltzberg S, Korbet S. Comparison of native and transplant kidney biopsies: diagnostic yield and complications. Clin Kidney J 2018;11:616-22.

${ }^{\S}$ Feldmann Y, Böer K, Wolf G, Busch M. Complications and monitoring of percutaneous renal biopsy - a retrospective study. Clin Nephrol 2018;89:260-8.

'Tsai SF, Chen CH, Shu KH, Cheng CH, Yu TM, Chuang YW, et al. Current safety of renal allograft biopsy with indication in adult recipients: an observational study. Med 2016;95:e2816.

'Morgan TA, Chandran S, Burger IM, Zhang CA, Goldstein RB. Complications of ultrasound-guided renal transplant biopsies. Am J Transpl 2016;16:1298-305. 
times and objective measurements of platelet function do not corelate with the development of bleeding complications during renal biopsies. ${ }^{31-33}$

The risk of biopsy-associated bleeding complications may be lower in transplanted kidneys than native kidneys. ${ }^{12,34}$ Renal allograft biopsies may be less challenging technically as transplanted kidneys are located more superficially and do not move with respiration. Any bleeding that occurs may potentially be more easily controlled with direct manual compression. Renal arteriolar vasoconstriction and the reduction of renal blood flow with the use of calcineurin inhibitors ${ }^{35}$ may also possibly attenuate the risk of bleeding during renal allograft biopsies. As such, evidence from studies involving native renal biopsies may not necessarily apply to renal allograft biopsies and the risk-to-benefit ratio for DDAVP use may be different.

Our study may not have been able to demonstrate a significant difference in the bleeding risk between the 2 groups due to a higher proportion of cases with risk factors for bleeding such as renal impairment and anaemia in the DDAVP group. Moreover, due to a low event rate of $8.2 \%$

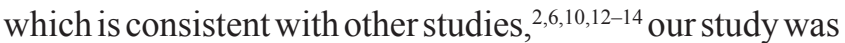
not adequately powered to detect the effect of DDAVP on bleeding and statistical adjustment of possible confounders was limited. However, a study adequately powered to detect an effect size of $50 \%$ would have required a sample size of at least 411 -assuming an event rate of $10 \%$, a 1-sided alpha error rate of $5 \%$ and power of $80 \%$. Furthermore, our study did show a trend towards lower risk of peri-nephric haematoma in the DDAVP group, raising the possibility of a type 2 error, even though repeat imaging was not routine. However, despite adjustment for renal function and each of the risk factors of bleeding, DDAVP still did not alter the bleeding risk.

DDAVP may also not have been shown to reduce bleeding in our study because the median dose received at $0.2 \mu \mathrm{g} /$ $\mathrm{kg}$, was lower than the $0.3-0.4 \mu \mathrm{g} / \mathrm{kg}$ dose typically used for prevention of uraemic bleeding. ${ }^{36} \mathrm{~A}$ previous RCT suggested a dose effect when it showed that $0.4 \mu \mathrm{g} / \mathrm{kg}$ of DDAVP resulted in fewer blood transfusions compared with $0.2 \mu \mathrm{g} / \mathrm{kg}$ of DDAVP in rheumatoid arthritis patients undergoing hip arthroplasty. ${ }^{37}$

DDAVP is not without risk. Reported adverse effects include headache, giddiness, nausea, flushing, abdominal pain, diarrhoea, hypotension, tachycardia and hyponatraemia. ${ }^{20,21}$ While previous studies involving native renal biopsies were not associated with major adverse events, ${ }^{15,16}$ severe hyponatraemia with neurological complications have been reported following the administration of DDAVP prior to renal allograft biopsies. ${ }^{17}$ Fluid restriction 1 hour prior to and 9 hours after the administration of DDAVP has been recommended to prevent hyponatraemia. ${ }^{17}$

In addition to conditions that may also affect the nontransplant population (such as cardiac failure and liver cirrhosis), renal transplant recipients may be exposed to other factors and medications that predispose them to hyponatraemia. ${ }^{38}$ Early post-transplant hyponatraemia may result from the use of hypotonic solutions and tubular sodium loss from hypoxic-ischaemic allograft injury. ${ }^{38}$ Renal impairment, along with tubular dysfunction, from allograft rejection or drug-induced interstitial nephritis (e.g. cotrimoxazole $)^{40}$ may affect urine sodium absorption and free water excretion. Cyclosporine has been reported to reduce proximal sodium tubular reabsorption while tacrolimus may cause salt-losing nephropathy by inducing aldosterone resistance. ${ }^{41-44}$ High-dose corticosteroids or calcineurin inhibitors may lead to drug-induced hyperglycaemia ${ }^{45}$ and hypertonic hyponatraemia. IVIG is known to cause both pseudo-hyponatraemia and "true" hypo-osmolar hyponatraemia. ${ }^{46,47}$ Therefore, renal transplant recipients may be at higher risk of developing hyponatraemia following administration ofDDAVP than the non-transplant population.

Fluid intake of $<1 \mathrm{~L}$ was associated with lower incidence of hyponatraemia and no cases of severe hyponatraemia, suggesting fluid restriction may be protective of DDAVP-associated hyponatraemia. Recommendation for fluid restriction of $<1 \mathrm{~L}$ over 24 hours, after DDAVP administration for renal biopsy should be considered, if possible. Lower baseline serum sodium levels and recent IVIG use were also associated with development of hyponatraemia suggesting DDAVP should be used with caution in patients with these risk factors.

Several cases of acute myocardial infarction following a single dose of DDAVP have also been reported. ${ }^{18} \mathrm{~A}$ previous systematic review on the use of DDAVP to decrease perioperative blood loss during cardiac surgeries also showed an increased risk of myocardial infarctions, ${ }^{19}$ though this association was not found in more recent meta-analyses ${ }^{48,49}$ Given that ischaemic heart disease is common in renal transplant recipients, DDAVP should be used with caution ${ }^{50}$ although there were no thrombotic events in our study.

Given its single-centre, retrospective nature, our study is prone to bias and confounding and its generalisability is limited. Our study consisted mainly of patients of Asian descent and its results may not apply to other ethnicities. DDAVP use and fluid management were not standardised and repeat investigations including imaging, serum and urine osmolarity were not routine. However, to our knowledge, this is the first study investigating the efficacy and safety of DDAVP for the prevention of bleeding complications 
during renal allograft biopsies. Our study also has one of the largest samples of prebiopsy DDAVP use in renal transplant recipients. Moreover, the results persisted after adjustment for possible confounders within the limitations of our dataset.

\section{Conclusion}

The effect of using intravenous DDAVP to reduce bleeding risk during renal allograft biopsy is unclear and may increase the risk of hyponatraemia. If DDAVP is used, we suggest that patients be fluid-restricted and monitored for complications such as hyponatraemia. We call for an adequately powered prospective RCT in the renal transplant population to clarify these outcomes.

\section{REFERENCES}

1. Williams WW, Taheri D, Tolkoff-Rubin N CR. Clinical role of the renal transplant biopsy. Nat Rev Nephrol 2012;8:110-21.

2. Redfield RR, McCune KR, Rao A, Sadowski E, Hanson M, Kolterman $\mathrm{AJ}$, et al. Nature, timing and severity of complications from ultrasoundguided percutaneous renal transplant biopsy. Transpl Int 2016;29:167-72.

3. Luciano RL, Moeckel GW. Update on the Native Kidney Biopsy : Core Curriculum 2019. Am J Kidney Dis 2019;5:941-7.

4. Vathsala A, Chow K. Renal transplantation in Singapore. Ann Acad Med Singapore 2009;38:291-9.

5. Vathsala A. Preventing renal transplant failure. Ann Acad Med Singapore 2005;34:36-43.

6. Tsai SF, Chen CH, Shu KH, Cheng CH, Yu TM, Chuang YW, et al. Current safety of renal allograft biopsy with indication in adult recipients: an observational study. Med 2016;95:e2816.

7. Chung J, Caumartin Y, Warren J, Luke PP. Acute Page kidney following renal allograft biopsy: a complication requiring early recognition and treatment. Am J Transpl 2008;8:1323-8.

8. Simard-Meilleur MC, Troyanov S, Roy L, Dalaire E, Brachemi S. Risk factors and timing of native kidney biopsy complications. Nephron Extra 2014;4:42-9.

9. Maya ID, Allon M. Percutaneous renal biopsy: outpatient observation without hospitalization is safe. Semin Dial 2009;22:458-61.

10. Plattner BW, Chen P, Cross R, Leavitt MA, Killen PD, Heung M. Complications and adequacy of transplant kidney biopsies: a comparison of techniques. J Vasc Access 2018;19:291-6.

11. Ferrandiz I, Congy-Jolivet N, Del Bello A, Debiol B, Trébern-Launay $\mathrm{K}$, Esposito L, et al. Impact of early blood transfusion after kidney transplantation on the incidence of donor-specific anti-HLA antibodies. Am J Transpl 2016;16:2661-9.

12. Whittier WL, Gashti C, Saltzberg S, Korbet S. Comparison of native and transplant kidney biopsies: diagnostic yield and complications. Clin Kidney J 2018;11:616-22.
13. Baffour FI, Hickson LJ, Stegall MD, Dean PG, Gunderson TM, Atwell TD, et al. Effects of aspirin therapy on ultrasound-guided renal allograft biopsy bleeding complications. J Vasc Interv Radiol 2017;28:188-94.

14. Morgan TA, Chandran S, Burger IM, Zhang CA, Goldstein RB. Complications of ultrasound-guided renal transplant biopsies. Am J Transpl 2016;16:1298-305.

15. Manno C, BonifatiC, Torres DD. Kidney biopsy: a randomized controlled trial. AJKD. 2011;57:850-5.

16. Peters B, Hadimeri H, Mölne J, Nasic S, Jensen G, Stegmayr B. Desmopressin $\left(\right.$ Octostim $\left.^{\circledast}\right)$ before a native kidney biopsy can reduce the risk for biopsy complications in patients with impaired renal function: a pilot study. Nephrol 2018;23:366 - 70.

17. Anandagoda N, Jayawardene S, Macdougall IC, Shah S. Desmopressin use prior to renal transplant biopsy - does it fit? Clin Kidney J 2014; 7:602-4.

18. Shah SN, Tran HA, Assal A, Ascunce RR, Yatskar L, Berger JS. In-stent thrombosis following DDAVP administration: case report and review of the literature. Blood Coagul Fibrinolysis 2014;25:81-3.

19. Levi M, Cromheecke ME, de Jonge E, Prins MH, de Mol BJ, Briët E, et al. Pharmacological strategies to decrease excessive blood loss in cardiac surgery: a meta-analysis of clinically relevant endpoints. Lancet 1999;354:1940-7.

20. Stoof SC, Cnossen MH, de Maat MP, Leebeek FW, Kruip MJ. Side effects of desmopressin in patients with bleeding disorders. Haemophilia 2016;22:39-45.

21. Vande Walle J, Stockner M, Raes A, Nørgaard JP. Desmopressin 30 years in clinical use: a safety review. Curr Drug Saf 2007;2:232-8.

22. Yablon Z, Recupero P, McKenna J, Vella J, Parker MG. Kidney allograft biopsy: timing to complications. Clin Nephrol 2010;74:39-45.

23. Ruzicka H, Björkman S, Lethagen S, Sterner G. Pharmacokinetics and antidiuretic effect of high-dose desmopressin in patients with chronic renal failure. Pharmacol Toxicol 2003;92:137-42.

24. Liamis G, Milionis H, Elisaf M. A review of drug-induced hyponatremia. Am J Kidney Disfs 2008;52:144-53.

25. R Core Team [2018]. R: A language and environment for statistical computing. R Foundation for Statistical Computing, Vienna, Austria. https://www.Rproject.org/.

26. Radhakrishnan S, Chanchlani R, Connolly B, Langlois V. Pre-procedure desmopressin acetate to reduce bleeding in renal failure: does it really work? Nephron Clin Pr 2014;128:45-8.

27. Kaufmann JE, Vischer UM. Cellular mechanisms of the hemostatic effects of desmopressin (DDAVP). J Thromb Haemost 2003;1:682-9.

28. Mannucci PM, Remuzzi G, Pusineri F, Lombardi R, Valsecchi C, Mecca $\mathrm{G}$, et al. Deamino-8-D-arginine vasopressin shortens the bleeding time in uremia. N Engl J Med 1983;308:8-12.

29. Ozen S, Saatci U, Bakkaloglu A, Ozdemir S, Ozdemir O, Besbas N. Low-dose intranasal desmopressin (DDAVP) for uremic bleeding. Nephron 1997;75:119-20.

30. Kim JH, Baek CH, Min JY, Kim JS, Kim SB, Kim H. Desmopressin improves platelet function in uremic patients taking antiplatelet agents who require emergent invasive procedures. Ann Hematol 2015;94:1457-61.

31. Stiles KP, Hill C, LeBrun CJ, Reinmuth B, Yuan CM, Abbott KC. The impact of bleeding times on major complication rates after percutaneous real-time ultrasound-guided renal biopsies. J Nephrol 2001;14:275-9.

32. Lehman CM, Blaylock RC, Alexander DP, Rodgers GM. Discontinuation of the bleeding time test without detectable adverse clinical impact. Clin Chem 2001;47:1204-11.

33. Islam N, Fulop T, Zsom L, Miller E, Mire CD, Lebrun CJ, et al. Do platelet function analyzer-100 testing results correlate with bleeding events after percutaneous renal biopsy? Clin Nephrol 2010;73:229-37.

34. Šimunov B, Gunjača M, Čingel B, Škegro D, Knotek M. Safety of outpatient kidney biopsies. Nephron 2018;138:275-9. 
35. Naesens M, Kuypers DR, Sarwal M. Calcineurin inhibitor nephrotoxicity. Clin J Am Soc Nephrol 2009;4:481-508.

36. Hedges SJ, Dehoney SB, Hooper JS, Amanzadeh J, Busti AJ. Evidencebased treatment recommendations for uremic bleeding. Nat Clin $\mathrm{Pr}$ Nephrol 2007;3:138-53.

37. Leino KA, Pälve HK, Tiusanen HT, Tuppurainen TT. The effect of desmopressin on blood loss in patients with rheumatoid arthritis undergoing hip arthroplasty. Acta Anaesthesiol Scand 2010;54:863-70.

38. Musso CG, Casta A, Mombelli C, Groppa S, Imperiali N, Diez GR. Hyponatremia in kidney transplant patients: its pathophysiologic mechanisms. Clin Kidney J 2018;11:581-5.

39. Zaltzman JS. Post-renal transplantation hyponatremia. Am J Kidney Dis 1996;27:599-602.

40. Herzog AL, Wanner C, Lopau K. Successful short-term intravenous treatment of disseminated nocardia farcinica Infection with severe hyponatremia after kidney transplantation: a case report. Transplant Proc 2016;48:3115-9.

41. Damiano S, Scanni R, Ciarcia R, Florio S, Capasso G. Regulation of sodium transporters in the kidney during cyclosporine treatment. J Nephrol 2010;23 Suppl 16:S191-8.

42. Bagchi S, Husain Zaidi, Prasad Mathur R. Severe symptomatic hyponatremia-an uncommon presentation of tacrolimus nephrotoxicity. Nephrol Dial Transpl 2011;26:2042-4.
43. Einollahi B, Nemati E, Rostami Z, Teimoori M, GhadianAR. Electrolytes disturbance and cyclosporine blood levels among kidney transplant recipients. Int J Organ Transpl Med 2012;3:166-75.

44. Higgins R, Ramaiyan K, Dasgupta T, Kanji H, Fletcher S, Lam F, et al. Hyponatraemia and hyperkalaemia are more frequent in renal transplant recipients treated with tacrolimus than with cyclosporin. Further evidence for differences between cyclosporin and tacrolimus nephrotoxicities. Nephrol Dial Transpl 2004;19:444-50.

45. Hoang TD, Bao VQ, Phat VH. Massive polyuria after kidney transplantation. Pediatr Nephrol 2010;25:383-4.

46. Lawn N, Wijdicks EF, Burritt MF. Intravenous immune globulin and pseudohyponatremia. N Engl J Med 1998;339:632.

47. Nguyen MK, Rastogi A, Kurtz I. True hyponatremia secondary to intravenous immunoglobulin. Clin Exp Nephrol 2006;10:124-6.

48. Desborough MJ, Oakland KA, Landoni G, Crivellari M, Doree C, Estcourt LJ. Desmopressin for treatment of platelet dysfunction and reversal of antiplatelet agents: a systematic review and meta-analysis of randomized controlled trials. J Thromb Haemost 2017;15:263-72.

49. Desborough MJ, Oakland K, Brierley C, Bennett S, Doree C, Trivella M, et al. Desmopressin use for minimising perioperative blood transfusion. Cochrane Database Syst Rev 2017;10:CD001884.

50. Lees JS, Mcquarrie EP, Mordi N, Geddes CC, Fox JG, Mackinnon B. Risk factors for bleeding complications after nephrologist-performed native renal biopsy. 2017;10:573-7.

Supplementary Table 1. Univariable Modelling for Overall Bleeding Complications

\begin{tabular}{|c|c|c|c|c|c|}
\hline Variable & $\begin{array}{l}\text { Bleeding } \\
(n=16)\end{array}$ & $\begin{array}{l}\text { Non-Bleeding } \\
\quad(n=179)\end{array}$ & $\begin{array}{l}\text { Odds } \\
\text { Ratio }\end{array}$ & $\begin{array}{l}\text { 95\% Confidence } \\
\text { Interval }\end{array}$ & $\begin{array}{c}P \\
\text { Value }\end{array}$ \\
\hline Age, year (IQR) & $51.6(15.3)$ & $50.5(13.5)$ & 1.00 & $0.96-1.05$ & 0.98 \\
\hline Males (vs females), n (\%) & $10(62.5)$ & $99(55.3)$ & 1.35 & $0.48-4.11$ & 0.58 \\
\hline \multicolumn{6}{|l|}{ Ethnicity, n (\%) } \\
\hline Chinese & $10(62.5)$ & $119(66.5)$ & - & - & - \\
\hline Indian & $2(12.5)$ & $14(7.8)$ & 1.70 & $0.25-7.33$ & 0.52 \\
\hline Others & $2(12.5)$ & $6(3.4)$ & 3.97 & $0.53-20.05$ & 0.12 \\
\hline \multicolumn{6}{|l|}{ Cause of ESRD, n (\%) } \\
\hline Glomerulonephritis & $9(56.3)$ & $128(71.5)$ & - & - & - \\
\hline Hypertension & $2(12.5)$ & $11(6.1)$ & 2.59 & $0.36-11.72$ & 0.26 \\
\hline Others & $0(0)$ & $33(18.4)$ & NA & NA & NA \\
\hline DDRT (versus LDRT), n (\%) & $10(62.5)$ & $111(62.7)$ & 0.99 & $0.34-2.85$ & 0.99 \\
\hline Years since transplant, years (IQR) & $0.6(8.7)$ & $4.2(9.5)$ & 0.95 & $0.86-1.03$ & 0.14 \\
\hline \multicolumn{6}{|l|}{ Maintenance immunosuppression, n (\%) } \\
\hline Prednisolone & $15(93.8)$ & $178(99.4)$ & 0.08 & $0.005-1.42$ & 0.09 \\
\hline Tacrolimus & $8(50)$ & $88(49.2)$ & 1.03 & $0.37-2.88$ & 0.95 \\
\hline Cyclosporin A & $7(43.8)$ & $74(41.3)$ & 1.10 & $0.39-3.10$ & 0.85 \\
\hline Mycophenolate & $15(93.8)$ & $139(77.7)$ & 4.32 & $0.55-33.68$ & 0.16 \\
\hline Azathioprine & $0(0)$ & $12(6.7)$ & NA & NA & NA \\
\hline Everolimus & $1(6.3)$ & $13(7.3)$ & 0.85 & $0.10-6.96$ & 0.88 \\
\hline Sirolimus & $0(0)$ & $6(3.4)$ & NA & NA & NA \\
\hline
\end{tabular}

aPTT: Activated partial thromboplastin time; BP: Blood pressure; DDAVP: Desmopressin acetate; DDRT: Deceased donor renal transplant; eGFR:

Estimated glomerular filtration rate; ESRD: End-stage renal disease; IQR: Interquartile range; IVIG: Intravenous immunoglobulin; LDRT: Living donor renal transplant; NA: Not applicable; PT: Prothrombin time 
Supplementary Table 1. Univariable Modelling for Overall Bleeding Complications (Cont'd)

\begin{tabular}{|c|c|c|c|c|c|}
\hline Variable & $\begin{array}{l}\text { Bleeding } \\
(n=16)\end{array}$ & $\begin{array}{l}\text { Non-Bleeding } \\
\quad(n=179)\end{array}$ & $\begin{array}{l}\text { Odds } \\
\text { Ratio }\end{array}$ & $\begin{array}{l}\text { 95\% Confidence } \\
\text { Interval }\end{array}$ & $\begin{array}{c}P \\
\text { Value }\end{array}$ \\
\hline \multicolumn{6}{|l|}{ Comorbidities, n (\%) } \\
\hline Hypertension & $15(93.8)$ & $133(74.3)$ & 5.19 & $1.01-95.1$ & 0.12 \\
\hline Diabetes mellitus & $6(37.5)$ & $41(22.9)$ & 2.02 & $0.65-5.78$ & 0.20 \\
\hline Ischaemic heart disease & $0(0)$ & $16(8.9)$ & NA & NA & NA \\
\hline Congestive cardiac failure & $0(0)$ & $0(0)$ & NA & NA & NA \\
\hline Liver cirrhosis & $0(0)$ & $0(0)$ & NA & NA & NA \\
\hline \multicolumn{6}{|l|}{ Clinical parameters } \\
\hline Weight, kg (IQR) & $65(19.7)$ & $67.7(21.1)$ & 0.99 & $0.96-1.02$ & 0.56 \\
\hline Body mass index (IQR) & $23.1(4.2)$ & $25.4(6.2)$ & 0.97 & $0.88-1.07$ & 0.60 \\
\hline Diastolic BP, mmHg (IQR) & $75(15.2)$ & $77(10.0)$ & 1.01 & $0.96-1.06$ & 0.69 \\
\hline \multicolumn{6}{|l|}{ Prebiopsy laboratory } \\
\hline Haemoglobin, g/dL (IQR) & $9.6(2.7)$ & $10.5(2.3)$ & 0.73 & $0.53-0.98$ & 0.04 \\
\hline Platelets, × 10/L (IQR) & $189(68.7)$ & $236(117.5)$ & 0.99 & $0.98-1.00$ & 0.002 \\
\hline PT, seconds (IQR) & $10.6(1.0)$ & $10.3(0.7)$ & 1.94 & $0.87-4.26$ & 0.11 \\
\hline aPTT, seconds (IQR) & $27.3(4.0)$ & $26.7(2.9)$ & 1.17 & $0.94-1.45$ & 0.16 \\
\hline Urea, mmol/L (IQR) & $13.2(6.5)$ & $13.3(6.1)$ & 0.99 & $0.88-1.09$ & 0.80 \\
\hline Creatinine, $\mu \mathrm{mol} / \mathrm{L}(\mathrm{IQR})$ & $294(256.7)$ & $229(126.5)$ & 1.00 & $1.00-1.01$ & 0.13 \\
\hline eGFR, mL/min/1.73 m² (IQR) & $18.4(19.6)$ & $23.7(15.1)$ & 0.98 & $0.93-1.03$ & 0.43 \\
\hline Urine protein-to-creatinine ratio, g/g (IQR) & $0.5(2.8)$ & $1(3.1)$ & 1.01 & $0.84-1.15$ & 0.85 \\
\hline Nephrotic range proteinuria, n (\%) & $4(30.8)$ & $56(33.3)$ & 0.89 & $0.26-3.01$ & 0.85 \\
\hline \multicolumn{6}{|l|}{ Medication use } \\
\hline Anticoagulation, n (\%) & $0(0)$ & $0(0)$ & NA & NA & NA \\
\hline Fresh frozen plasma, n (\%) & $1(6.3)$ & $1(0.6)$ & 11.87 & $0.45-310.42$ & 0.09 \\
\hline Vitamin K, n (\%) & $0(0)$ & $1(0.6)$ & NA & NA & NA \\
\hline Antihypertensive, n (\%) & $13(81.3)$ & $151(84.4)$ & 0.8 & $0.24-3.67$ & 0.75 \\
\hline DDAVP, n (\%) & $8(50.0)$ & $90(50.3)$ & 0.99 & $0.35-2.8$ & 0.98 \\
\hline Dose of DDAVP, mg (IQR) & $16(4.0)$ & $12(4.0)$ & 1.12 & $0.88-1.39$ & 0.34 \\
\hline Dose of DDAVP per body weight, mg/kg (IQR) & $0.2(0)$ & $0.2(0)$ & 24.34 & $0-55107336.18$ & 0.68 \\
\hline
\end{tabular}

aPTT: Activated partial thromboplastin time; BP: Blood pressure; DDAVP: Desmopressin acetate; DDRT: Deceased donor renal transplant; eGFR:

Estimated glomerular filtration rate; ESRD: End-stage renal disease; IQR: Interquartile range; IVIG: Intravenous immunoglobulin; LDRT: Living donor renal transplant; NA: Not applicable; PT: Prothrombin time 
Supplementary Table 2. Multivariable Modelling for Overall Bleeding Complications With Desmopressin Acetane Use as Co-Variate

\begin{tabular}{|c|c|c|c|}
\hline Variable & Adjusted Odds Ratio & 95\% Confidence Interval & $P$ Value \\
\hline \multicolumn{4}{|l|}{ DDAVP adjusted by eGFR } \\
\hline DDAVP & 0.79 & $0.26-2.43$ & 0.68 \\
\hline $\mathrm{eGFR}, \mathrm{mL} / \mathrm{min} / 1.73 \mathrm{~m}^{2}$ & 0.98 & $0.93-1.03$ & 0.37 \\
\hline \multicolumn{4}{|l|}{ DDAVP adjusted by urea } \\
\hline DDAVP & 1.06 & $0.34-3.27$ & 0.93 \\
\hline \multicolumn{4}{|l|}{ DDAVP adjusted by creatinine } \\
\hline DDAVP & 0.69 & $0.23-2.12$ & 0.52 \\
\hline Creatinine, $\mu \mathrm{mol} / \mathrm{L}$ & 1.003 & $1.00-1.01$ & 0.08 \\
\hline \multicolumn{4}{|l|}{ DDAVP adjusted by diuretic use } \\
\hline DDAVP & 0.93 & $0.32-2.67$ & 0.89 \\
\hline \multicolumn{4}{|c|}{ DDAVP adjusted by DM as cause of ESRD } \\
\hline DDAVP & 1.24 & $0.41-3.70$ & 0.70 \\
\hline DM as cause of ESRD (vs others) & 11.65 & $3.10-43.75$ & $<0.001$ \\
\hline \multicolumn{4}{|l|}{ DDAVP adjusted by haemoglobin } \\
\hline DDAVP & 0.84 & $0.30-2.39$ & 0.75 \\
\hline Haemoglobin, g/dL & 0.72 & $0.53-0.99$ & 0.04 \\
\hline \multicolumn{4}{|l|}{ DDAVP adjusted by platelet } \\
\hline DDAVP & 1.10 & $0.38-3.16$ & 0.86 \\
\hline Platelet, $\times 10^{9} / \mathrm{L}$ & 0.99 & $0.979-0.996$ & 0.006 \\
\hline \multicolumn{4}{|l|}{ DDAVP adjusted by FFP } \\
\hline DDAVP & 0.88 & $0.30-2.52$ & 0.80 \\
\hline FFP & 12.71 & $0.72-225.73$ & 0.08 \\
\hline DDAVP & 0.99 & $0.35-2.79$ & 0.98 \\
\hline Prednisolone & 0.084 & $0.005-1.42$ & 0.08 \\
\hline
\end{tabular}

DDAVP: Desmopressin acetane; DM: Diabetes mellitus; eGFR: Estimated glomerular filtration rate; ESRD: End-stage renal disease; FFP: Fresh frozen plasma 
Supplementary Table 3. Univariable Modelling for Hyponatraemia

\begin{tabular}{|c|c|c|c|c|c|}
\hline Variable & $\begin{array}{l}\text { Hyponatraemia } \\
(n=70)\end{array}$ & $\begin{array}{c}\text { Non- } \\
\text { Hyponatraemia } \\
(\mathrm{n}=107)\end{array}$ & $\begin{array}{l}\text { Odds } \\
\text { Ratio }\end{array}$ & $\begin{array}{c}95 \% \\
\text { Confidence } \\
\text { Interval }\end{array}$ & $\begin{array}{c}P \\
\text { Value }\end{array}$ \\
\hline Age, year (IQR) & $50.1(12.7)$ & $50.5(16.2)$ & 0.99 & $0.97-1.02$ & 0.62 \\
\hline Males (vs females), n (\%) & $40(57.1)$ & $60(56.1)$ & 1.04 & $0.57-1.92$ & 0.89 \\
\hline \multicolumn{6}{|l|}{ Ethnicity, n (\%) } \\
\hline Chinese & $44(62.9)$ & $73(68.2)$ & - & - & - \\
\hline Malay & $18(25.7)$ & $20(18.7)$ & 1.49 & $0.71-3.13$ & 0.29 \\
\hline Indian & $4(5.7)$ & $10(9.3)$ & 0.66 & $0.20-2.24$ & 0.51 \\
\hline Others & $4(5.7)$ & $4(3.7)$ & 1.66 & $0.40-6.97$ & 0.49 \\
\hline \multicolumn{6}{|l|}{ Cause of ESRD, n (\%) } \\
\hline Glomerulonephritis & $47(67.1)$ & $77(72.0)$ & - & - & - \\
\hline Hypertension & $4(5.7)$ & $7(6.5)$ & 0.94 & $0.26-3.37$ & 0.92 \\
\hline Others & $15(21.4)$ & $16(15.0)$ & 1.54 & $0.70-3.39$ & 0.29 \\
\hline DDRT (vs LDRT), n (\%) & $36(51.4)$ & $72(67.9)$ & 0.50 & $0.27-0.93$ & 0.03 \\
\hline Years since transplant, years (IQR) & $3.6(9.3)$ & $3.9(8.9)$ & 0.96 & $0.95-1.04$ & 0.81 \\
\hline \multicolumn{6}{|l|}{ Maintenance immunosuppression, n (\%) } \\
\hline Prednisolone & $70(100)$ & $105(98.1)$ & NA & NA & NA \\
\hline Tacrolimus & $40(57.1)$ & $52(48.6)$ & 1.41 & $0.77-2.59$ & 0.27 \\
\hline Cyclosporin A & $23(32.9)$ & $46(43.0)$ & 0.65 & $0.35-1.22$ & 0.18 \\
\hline Mycophenolate & $52(74.3)$ & $90(84.1)$ & 0.55 & $0.26-1.15$ & 0.11 \\
\hline Azathioprine & $3(4.3)$ & $7(6.5)$ & 0.64 & $0.16-2.56$ & 0.53 \\
\hline Everolimus & $7(10.0)$ & $7(6.5)$ & 1.59 & $0.53-4.74$ & 0.41 \\
\hline Sirolimus & $2(2.9)$ & $2(1.9)$ & 1.54 & $0.21-11.2$ & 0.67 \\
\hline Diabetes mellitus & $20(28.6)$ & $22(20.6)$ & 1.55 & $0.77-3.11$ & 0.22 \\
\hline Ischaemic heart disease & $6(8.6)$ & $7(6.5)$ & 1.34 & $0.43-4.17$ & 0.61 \\
\hline Hypothyroidism & $5(7.1)$ & $3(2.8)$ & 2.67 & $0.62-11.5$ & 0.19 \\
\hline Congestive cardiac failure & $0(0)$ & $0(0)$ & NA & NA & NA \\
\hline Liver cirrhosis & $0(0)$ & $0(0)$ & NA & NA & NA \\
\hline \multicolumn{6}{|l|}{ Clinical parameters } \\
\hline Weight, kg (IQR) & $69.1(21.6)$ & $66.5(23.1)$ & 1.002 & $0.98-1.02$ & 0.87 \\
\hline Body mass index (IQR) & $24.9(8.0)$ & $25.3(5.6)$ & 1.00 & $0.94-1.06$ & 0.99 \\
\hline Systolic BP, mmHg (IQR) & $128(20)$ & $130(20)$ & 1.00 & $0.98-1.01$ & 0.63 \\
\hline Diastolic BP, mmHg (IQR) & 79 (19) & $75(10)$ & 0.99 & $0.96-1.02$ & 0.51 \\
\hline \multicolumn{6}{|l|}{ Prebiopsy laboratory } \\
\hline Haemoglobin, g/dL (IQR) & $10.2(2.6)$ & $10.4(2.6)$ & 0.88 & $0.74-1.04$ & 0.14 \\
\hline Platelets, × 109/L (IQR) & $234(90)$ & $229(116)$ & 1.00 & $0.996-1.003$ & 0.90 \\
\hline Urea, mmol/L (IQR) & $13.9(6.7)$ & $13.2(6.4)$ & 1.02 & $0.96-1.08$ & 0.53 \\
\hline Creatinine, $\mu \mathrm{mol} / \mathrm{L}(\mathrm{IQR})$ & $261(160)$ & $233(184)$ & 1.00 & $0.998-1.003$ & 0.47 \\
\hline eGFR, mL/min/1.73 m² (IQR) & $21.1(15.8)$ & $23.5(15.5)$ & 0.99 & $0.96-1.02$ & 0.42 \\
\hline Urine protein-to-creatinine ratio, g/g (IQR) & $1.46(3.85)$ & $0.91(2.75)$ & 1.01 & $0.91-1.11$ & 0.92 \\
\hline Nephrotic range proteinuria, $\mathrm{n}(\%)$ & $23(36.5)$ & $32(31.4)$ & 1.26 & $0.65-2.44$ & 0.50 \\
\hline Sodium, mmol/L (IQR) & $137(2)$ & $139(4)$ & 0.75 & $0.66-0.85$ & $<0.001$ \\
\hline
\end{tabular}

BP: Blood pressure; DDAVP: Desmopressin acetane; DDRT: Deceased donor renal transplant; eGFR: Estimated glomerular filtration rate; ESRD: Endstage renal disease; IQR: Interquartile range; LDRT: Living donor renal transplant; NA: Not applicable 
Supplementary Table 3. Univariable Modelling for Hyponatraemia (Cont'd)

\begin{tabular}{|c|c|c|c|c|c|}
\hline Variable & $\begin{array}{l}\text { Hyponatraemia } \\
(\mathrm{n}=70)\end{array}$ & $\begin{array}{c}\text { Non- } \\
\text { Hyponatraemia } \\
(\mathrm{n}=107)\end{array}$ & $\begin{array}{l}\text { Odds } \\
\text { Ratio }\end{array}$ & $\begin{array}{c}95 \% \\
\text { Confidence } \\
\text { Interval }\end{array}$ & $\begin{array}{c}P \\
\text { Value }\end{array}$ \\
\hline \multicolumn{6}{|l|}{ Medication use } \\
\hline Antihypertensive, n (\%) & $54(77.1)$ & $92(86.0)$ & 0.55 & $0.25-1.20$ & 0.13 \\
\hline Diuretic, n (\%) & $17(24.3)$ & $40(37.4)$ & 0.54 & $0.27-1.05$ & 0.07 \\
\hline Loop diuretic, n (\%) & $17(24.3)$ & $38(35.5)$ & 0.58 & $0.30-1.14$ & 0.12 \\
\hline Thiazide diuretic, n (\%) & $1(1.4)$ & $2(1.9)$ & 0.77 & $0.07-8.68$ & 0.83 \\
\hline Potassium-sparing diuretic, n (\%) & $4(5.7)$ & $2(1.9)$ & 3.18 & $0.57-17.86$ & 0.19 \\
\hline Intravenous immunoglobulin, $\mathrm{n}(\%)$ & $7(10.0)$ & $3(2.8)$ & 3.85 & $0.96-15.44$ & 0.06 \\
\hline Opioid, n (\%) & $11(15.7)$ & $15(14.0)$ & 1.14 & $0.49-2.66$ & 0.76 \\
\hline Bactrim, n (\%) & $5(7.1)$ & $9(8.4)$ & 0.84 & $0.27-2.61$ & 0.76 \\
\hline Proton pump inhibitors, n (\%) & $7(10.0)$ & $9(8.4)$ & 1.21 & $0.43-3.41$ & 0.72 \\
\hline Ciprofloxacin, n (\%) & $3(4.3)$ & $3(2.8)$ & 1.55 & $0.30-7.92$ & 0.60 \\
\hline New sodium-lowering medications 2 weeks prior, $\mathrm{n}(\%)$ & $18(25.7)$ & $22(20.6)$ & 1.34 & $0.66-2.73$ & 0.42 \\
\hline Fluid intake on biopsy day, per 100 mL (IQR) & $16.8(11.2)$ & $11.0(10.8)$ & 1.04 & $1.004-1.08$ & 0.03 \\
\hline DDAVP, n (\%) & $43(61.4)$ & $49(45.8)$ & 1.89 & $1.02-3.48$ & 0.04 \\
\hline Dose of DDAVP, mg (IQR) & $13.0(4.0)$ & $12.0(4.0)$ & 1.10 & $0.96-1.27$ & 0.18 \\
\hline Dose of DDAVP per body weight, mg/kg (IQR) & $0.20(0.06)$ & $0.21(0.06)$ & 0.19 & $0.00-2005.71$ & 0.72 \\
\hline
\end{tabular}

BP: Blood pressure; DDAVP: Desmopressin acetane; DDRT: Deceased donor renal transplant; eGFR: Estimated glomerular filtration rate; ESRD: Endstage renal disease; IQR: Interquartile range; LDRT: Living donor renal transplant; NA: Not applicable

Supplementary Table 4. Multivariable Modelling for Hyponatraemia

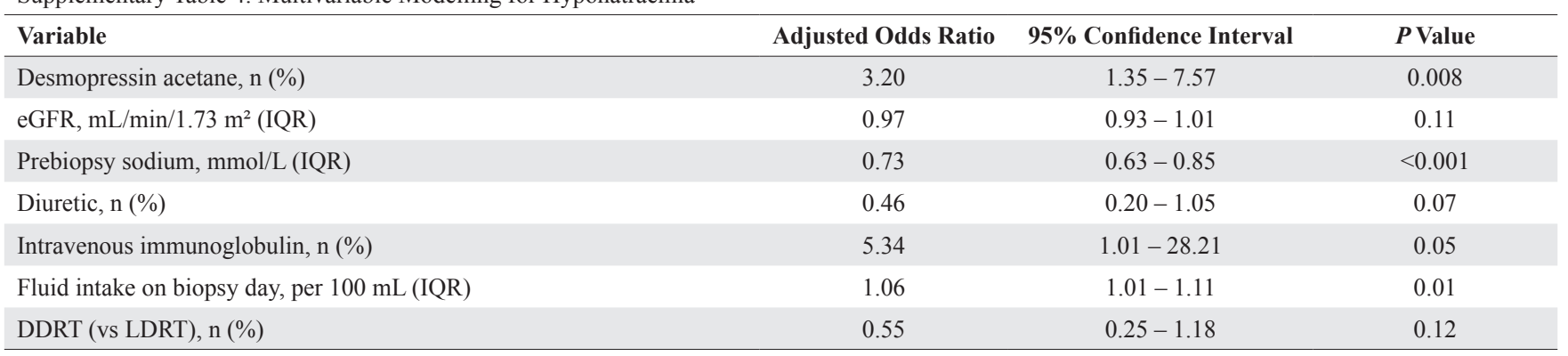

DDRT: Deceased donor renal transplant; eGFR: Estimated glomerular filtration rate; IQR: Interquartile range; LDRT: Living donor renal transplant 